\title{
JMSR
}

Journal of Medical and Scientific Research

\section{Comparative study of low density lipoprotein by estimation and calculation from lipid profile in a tertiary hospital}

\author{
Lavanya Lagisetty $^{1, *}$ and Radhika Chowdary Darapuneni ${ }^{1}$ \\ ${ }^{1}$ Department Laboratory Medicine, Krishna Institute of Medical Sciences, Minister Road, Secunderabad-500003, Telangana, India
}

\begin{abstract}
Introduction: Low-density lipoprotein cholesterol (LDL-C) is widely recognized as an established cardiovascular risk marker. Recent studies have shown that Friedewald underestimates LDL-C at lower levels, which could result in under treatment of high-risk patients of Atherosclerotic cardiovascular disease (ASCVD). A novel method Martin/Hopkins (LDL-CN) using a patient-specific conversion factor provides more accurate calculated LDL-C levels, LDL-C estimation is very important in high-risk patients to consider therapy.
\end{abstract}

Aims: To compare LDL-C values by using two formulae and direct estimation.

Materials and methods: A prospective study was undertaken in Department of Biochemistry in 1393 subjects from Dec 2018 to March 2019 with mean age of (53.23 \pm 13.36$)$. LDL-C was calculated by using Friedewald formula LDL-C (LDL-CF) and Martin/Hopkins equation (LDL-CN) in 1000 subjects with Triglycerides (TG) $<400 \mathrm{mg} / \mathrm{dl}$ and for 393 patients with TG>400 ldl was directly estimated (LDL-CD) with kit in Beckman coulter Dxc860i.

Results: For this analysis, the mean age was $(53.23 \pm 13.36)$. In 1000 patients, with $\mathrm{TG}<400 \mathrm{mg} / \mathrm{dl}$ the mean LDL-CF $(95.13 \pm 36.16 \mathrm{mg} / \mathrm{dl})$ was significantly lower compared to LDL-CN $(98.90 \pm 35.88 \mathrm{mg} / \mathrm{dl})$ with $p$ value (0.01). Thus, LDL-CN yielded a better diagnostic value than LDL-CF with regression of $r^{2}-0.94$. In 393 cases with $\mathrm{Tg}>400 \mathrm{mg} / \mathrm{dl}$, the mean of LDL-CF $(71.83 \pm 55.93 \mathrm{mg} / \mathrm{dl})$, was significantly lower compared to LDL-CD $(104.17 \pm 41.6 \mathrm{mg} / \mathrm{dl})$ and LDL-CN $(107.37 \pm 42.73 \mathrm{mg} / \mathrm{dl}) . p$ value was significant between Martin/Hopkins and Friedewald $(<0.0001)$ and it is significant between LDL-CD and LDL-CF $(<0.0001)$ but not between LDL-CD and LDL-CN (0.28).

Conclusion: This data suggest that Martin/Hopkins equation should be the preferred method to calculate LDL-C levels in with $\mathrm{TG}<400 \mathrm{mg} / \mathrm{dl}$ and either direct measurement or Martin/Hopkins are the preferred methods in patients with $\mathrm{TG}>400 \mathrm{mg} / \mathrm{dl}$ to treat high risk cases of ASCVD.

Keywords: Atherosclerotic cardiovascular disease; ASCVD; triglycerides; low density lipoprotein cholesterol

*Corresponding author: Dr. Lavanya Lagisetty, MD (Biochemistry), Department Laboratory Medicine, Krishna Institute of Medical Sciences, Minister Road, Secunderabad500003, Telangana, India. Email: lavanyamacha99@gmail.com

Received 11 November 2019; Revised 12 December 2019; Accepted 20 December 2019; Published 28 December 2019

Citation: Lagisetty L, Darapuneni RC. Comparative study of low density lipoprotein by estimation and calculation from lipid profile in a tertiary hospital. J Med Sci Res. 2020; 8(1):12-16. DOI: http://dx.doi.org/10.17727/JMSR.2020/8-2

Copyright: (C) 2020 Lagisetty L et al. Published by KIMS Foundation and Research Center. This is an open-access article distributed under the terms of the Creative Commons Attribution License, which permits unrestricted use, distribution, and reproduction in any medium, provided the original author and source are credited. 


\section{Introduction}

Low-density lipoprotein cholesterol (LDL-C) is a major modifiable risk factor for cardiovascular disease (CVD) [1], its accurate assessment is important for therapeutic decisions. In routine clinical practice worldwide, it is typically calculated using the Friedewald formula [2]. From the outset, the formula's inaccuracies at triglyceride levels at $400 \mathrm{mg} / \mathrm{dl}$ were recognized by Friedewald et al. [3]. However, even when triglyceride levels are under $400 \mathrm{mg} / \mathrm{dl}$, a number of studies have suggested that LDL-C estimated by the Friedewald formula (LDLCF) underestimate LDL-C and misclassify CVD risk [4-7], particularly in individuals with high levels of triglycerides [4-6] and LDL-C less than $70 \mathrm{mg} / \mathrm{dl}$ [7].

$\beta$-quantification, a time consuming and expensive technique, requires ultracentrifugation and large volume of sample is the reference method for the quantitative estimation of LDL-C in circulation. Therefore, this method is not suitable for routine laboratory testing [8].

Aless expensive and easy approach for the estimation of LDL-C include homogeneous direct measurement $[9,4]$ and Friedewald formula [3] worldwide.

In a study by Martin et al. [10], an alternative to the Friedewald formula was proposed to improve estimation of LDL-C at triglyceride levels under $400 \mathrm{mg} / \mathrm{dl}$. The Friedewald equation calculates LDL-C as LDL-CF = [total cholesterol]-[high-density lipoprotein cholesterol (HDL-C)] - [triglycerides/ 5], where the final term is the estimate of verylow- density lipoprotein cholesterol (VLDL-C). This equation therefore uses a fixed factor of 5 for the ratio of triglycerides to VLDL-C (TG: VLDL-C); however, the Martin equation applies an adjustable factor determined as the $\mathrm{N}$-strata-specific median
TG: VLDL-C ratio based on triglyceride and nonHDL-C concentrations to estimate the novel LDL-C (LDL-CN). Compared with LDL-CF, LDL-CN was reported to be closer to directly measured LDL-C (LDL-CD) and improved concordance in guideline risk classification with LDL-CD especially at LDL-C less than $70 \mathrm{mg} / \mathrm{dl}$.

The present study was designed to compare the LDL-C calculated by formulae which use HDL-C, total cholesterol (TC) and TG to calculate LDL-C with directly measured LDL-C with TG levels $<400 \mathrm{mg} /$ $\mathrm{dl}$ and $>400 \mathrm{mg} / \mathrm{dl}$ in Indian population with the assumption that the results obtained by direct assays are the most accurate.

\section{Materials and methods}

A prospective cross sectional study was undertaken for the out-patients and in-patients samples which had come for LDL-C estimation from the month of Dec 2018 to march 2019 at Krishna Institute of Medical Sciences (KIMS) Hospital, Secunderabad, India ( $\mathrm{n}=1393$ ). Samples of all age groups were taken into the study.

Serum lipid concentrations (Total cholesterol, HDL, TG, LDL-C) were directly measured using Beckman coulter in DXC 860i, an automated analyser. Standard operative procedures and quality control as described by the manufacturer were followed.

LDL-C was calculated with Friedewald formula and Martin/Hopkins formula for samples with $\mathrm{TG}<400 \mathrm{mg} / \mathrm{dl}$. LDL was measured and calculated with above formulae for $\mathrm{TG}>400 \mathrm{mg} / \mathrm{dl}$. All the values were analysed and recorded.

\section{Principle of directly measured LDL}

It is a homogeneous assay without the need for any off-line pre-treatment or centrifugation steps.

(Detergent 1) cholesterol esterase

\begin{tabular}{rll} 
HDL-C, VLDL-C, CM-C & \multicolumn{1}{c}{ Non-colour product } \\
& Cholesterol oxidase & \\
& (Detergent 2) cholesterol esterase & \\
LDL-C & $\stackrel{\Delta^{4} \text { cholestenone }+\mathrm{H}_{2} \mathrm{O}_{2}}{ }$ & \\
& Cholesterol oxidase & \\
& Peroxidase & colour product
\end{tabular}


The method depends on a unique detergent which solubilises only the non-LDL lipoprotein particles and releases cholesterol to react with cholesterol esterase and cholesterol oxidase to produce a non-colour forming reaction. A second detergent solubilises the remaining LDL particles, and a chromogenic coupler allows for colour formation.

\section{Statistical analysis}

The data was entered into an excel sheet and analysed. Descriptive statistics such as tables were used to describe the data. $p$ value were calculated wherever necessary for LDL estimated by Friedwalds formula and Mortin/Hopkins formula and direct estimation.

The aim was to compute the levels of differences between the methods. The probability of significance ( $p$ value) is considered significant less than 0.05 i.e., considering $\alpha=5$. The values are analysed in terms of mean, standard deviation, standard error of mean, paired sample $t$ test.

The approach was done by the paired $t$ test, because all parameters of the study were numerical, all patients came from the same population and all had paired results. The most appropriate formula would be the one that would produce the larger $p$, i.e. the formula that would produce results statistically insignificant among the Friedewald formula and Martin/ Hopkins equation.

\section{Results}

A total of 1393 lipid profiles were grouped into TG $<400 \mathrm{mg} / \mathrm{dl}(1000)$ and $\mathrm{TG}>400 \mathrm{mg} / \mathrm{dl}(\mathrm{N}=393)$. For TG range $<400 \mathrm{mg} / \mathrm{dl}$, presented in (Table 1 ), the mean value obtained from Mortin/Hopkins formula is more significant when compared with Friedewald formula with $r=0.948$ and mean difference of 3.77 with $(p=0.01)$. For TG range $>400 \mathrm{mg} / \mathrm{dl}$, presented in Tables 2, 3 \& 4. Friedewald equation showed high significant mean difference on comparison with Martins/Hopkins and direct estimation. Among the two formulae, the mean value obtained by Martin/Hopkins formula correlated best with direct measurement.

In Table 1, of 1000 patients, with $\mathrm{TG}<400 \mathrm{mg} /$ $\mathrm{dl}$ the mean of LDL-CF $(95.13 \pm 36.16 \mathrm{mg} / \mathrm{dl})$ was significantly lower compared to LDL-CN $(98.90 \pm 35.88 \mathrm{mg} / \mathrm{dl})$ with $p$ value $(0.01)$ with mean difference of 3.77. Thus, LDL-CN yielded a better diagnostic value than LDL-CF with regression of $r^{2}$ 0.94 .

Table 1: Comparison of mean values of LDL-C levels in samples of $\mathrm{TG}<400 \mathrm{mg} / \mathrm{dl}$ by two methods.

\begin{tabular}{|lcc|}
\hline Method & Mean $\pm S D$ & p value \\
\hline Friedewald formula & $95.13 \pm 36.16$ & 0.01 \\
Mortin/hopkins formula & $98.90 \pm 35.88$ & \\
\hline
\end{tabular}

Table 2: Comparison of mean values of LDL-C by Friedewald formula, Mortin/Hopkins formula and direct estimation in $\mathrm{TG}>400 \mathrm{mg} / \mathrm{dl}$ samples.

\begin{tabular}{|lcr|}
\hline Methods & Mean \pm SD & p value \\
\hline Friedewald formula & $71.83 \pm 55.93$ & \\
Mortin/hopkins formula & $107.37 \pm 42.73$ & $<0.0001$ \\
Direct estimation & $104.17 \pm 41.60$ & \\
\hline
\end{tabular}

In Table 2, of 393 cases with $\mathrm{TG}>400 \mathrm{mg} / \mathrm{dl}$, the mean of LDL-CF $(71.83 \pm 55.93 \mathrm{mg} / \mathrm{dl})$, was significantly lower compared to LDL-CD $(104.17 \pm 41.6 \mathrm{mg} / \mathrm{dl})$ and LDL-CN $(107.37 \pm 42.73 \mathrm{mg} / \mathrm{dl}) . p$ value was significant between Martin/Hopkins and Friedewald $(<0.0001)$ with mean difference of 35.54 .

Table 3: Comparison of mean values of LDL-C by Friedewald formula, and direct estimation in TG $>400 \mathrm{mg} / \mathrm{dl}$ samples.

\begin{tabular}{|lcc|}
\hline Methods & Mean $\pm S D$ & p value \\
\hline Friedewald formula & $71.83 \pm 55.93$ & \\
Direct estimation & $104.17 \pm 41.60$ & $<0.0001$ \\
\hline
\end{tabular}

In Table 3, of 393 cases with TG $>400 \mathrm{mg} / \mathrm{dl}$, the mean of LDL-CF $(71.83 \pm 55.93 \mathrm{mg} / \mathrm{dl})$, was significantly lower compared to LDL-CD $(104.17 \pm 41.6 \mathrm{mg} / \mathrm{dl})$. $p$ value was significant between direct estimation and Friedewald $(<0.0001)$ with mean difference of 32.34 .

Table 4: Comparison of mean values of LDL-C by Martin/ Hopkins formula and direct estimation in $\mathrm{TG}>400 \mathrm{mg} / \mathrm{dl}$ samples.

\begin{tabular}{|lcc|}
\hline Methods & Mean \pm SD & p value \\
\hline Direct estimation & $104.17 \pm 41.60$ & \\
Martin/Hopkins formula & $107.37 \pm 42.73$ & 0.28 \\
\hline
\end{tabular}


In Table 4, of 393 cases, $p$ value was not significant between LDL-CD and LDL-CN (0.28) as the difference in mean value is very less, stating that either Martin/ Hopkins formula or direct measurement can be used for measuring LDL-C in TG>400mg/dl.

\section{Discussion}

Friedewald formula is the formula of choice for LDL-C calculation in most laboratories across the world. Many studies have shown its limitation and some have shown that other equations perform better for certain groups of populations. Measurement of LDL-C is of wide interest and deeply ingrained in practice. Guidelines around the globe focus on the LDL-C cut points, including guidelines from the National heart, lung, and blood institute $[1,11,12]$. Canadian Cardiovascular Society [13], European Society of Cardiology and European Atherosclerosis Society [14] and the American Heart Association and American College of Cardiology [12, 15]. Some of these guidelines $[13,14]$ assign the highest level of evidence (Class $1 \mathrm{~A}$ ) to LDL-C treatment goals. LDL-C has been a focus in the inclusion criteria of numerous clinical trials, serially quantified during trials, and used as a target for drug titration in some trials [16, 17]. The Cholesterol Treatment Trialists summarize the totality of evidence for statin therapy as the risk reduction indexed to a $39 \mathrm{mg} / \mathrm{dl}$ lowering of LDL-C $[16,17]$.

In our study, with $\mathrm{TG}<400 \mathrm{mg} / \mathrm{dl}$ and $\mathrm{TG}>400 \mathrm{mg} /$ $\mathrm{dl} \mathrm{p}$ value is significant with Martin/Hopkins when compared to Friedewald formula $(p \leq 0.0001)$ which is in accordance with Martin et al. [19], showed greater accuracy with the novel calculation method (Martin/Hopkins) for all clinical LDL-C categories (87-94\%) vs Friedewald estimation (71-93\%) in both fasting and non-fasting samples $(p \leq 0.001)$.

In the derivation study, overall accuracy of the Martin/Hopkins equation compared to direct ultracentrifugation was $92 \%$ in contrast to $85 \%$ accuracy for Friedewald estimation $(p<0.001)$ [12] as same as our study.

Our results indicate that Friedewald formula fails to provide a good result at $\mathrm{TG}>400 \mathrm{mg} / \mathrm{dl}$. This is contradictory to the study done by Sha et al. [18], in Bangladeshi population which concluded that Friedewald formula can be used up to serum TG concentration of $700 \mathrm{mg} / \mathrm{dl}$. In a study [19], the Martin/Hopkins method provides a more accurate estimate of LDL-C levels than Friedwalds formula in $\mathrm{LDL}<40 \mathrm{mg} / \mathrm{dl}$ is in accordance with our study.

In a study [20], the novel equation provides a higher estimation of exact LDL-C values than the Friedewald equation, particularly in patients with low LDL-C levels, which may result in under treatment of some patients whose LDL-C was calculated using the Friedewald method. However, neither may be suitable for patients with $\mathrm{TG} \geq 400$ $\mathrm{mg} / \mathrm{dl}$ is in accordance with our study saying direct measurement provides better results of LDL-C than calculations.

\section{Conclusion}

Estimates by Martin/Hopkins equation is superior to Friedewald equation for estimating LDL-C concentrations in adults in $\mathrm{TG}<400 \mathrm{mg} / \mathrm{dl}$. Direct measurement and Martin/Hopkins formulae are better than Friedewald in TG $>400 \mathrm{mg} / \mathrm{dl}$. The result of the current study becomes clinically relevant in two ways. Patients who have their LDL-C underestimated may lead to delay in initiation of adequate lipid- lowering therapy in high risk patients as the practitioner is led to believe that the calculated LDL-C is indeed low, when it is not. On the other hand, when LDL-C is overestimated at higher levels, placing the patient in higher risk strata, it results in unnecessary pharmacological therapy.

\section{Study limitations}

This study compares calculated LDL-C with direct LDL-C assay and not with the reference method i.e., ultracentrifuge and precipitation for comparison. Also, the study uses only one assay for TG, TC, LDL-C and HDL-C and other assay methods have not been considered. Another limitation is that the number of samples with TG>400mg/dl was small. Factors such as race/ethnicity, obesity, diabetes, and insulin resistance, which may affect variance in the TG: VLDL-C ratio, were not available for analysis. It is unknown to what extent patients in our study sample were treated with lipid-modifying drug therapies. A multicentre, prospective study should be conducted to expand the knowledge gained from this study. Lifestyle modification and public education are recommended for prevention of CVD. 


\section{Conflict of interest}

The authors declare no conflicts of interest.

\section{References}

[1] Expert panel on detection, evaluation, and treatment of high blood cholesterol in adults. Executive summary of the third report of the national cholesterol education program (NCEP) expert panel on detection, evaluation, and treatment of high blood cholesterol in adults (Adult Treatment Panel III). JAMA 2001; 285(19):2486-2497.

[2] Stein EA. Measuring LDL cholesterol: for old and new calculations, is there an optimal formula? Chin Chem 2014; 60(12):1466-1468.

[3] Friedewald WT, Levy RI, Fredrickson DS. Estimation of the concentration of low-density lipoprotein cholesterol in plasma, without use of the preparative ultracentrifuge. Clin Chem 1972; 18(6):499-502.

[4] Nauck M, Warnick GR, Rifai N. Methods for measurement of LDL-cholesterol: a critical assessment of direct measurement by homogenous assays versus calculation. Clin Chem 2002; 48(2):236-254.

[5] Martin SS, Blaha MJ, Elshazly MB, Brinton EA, Toth PP, et al. Friedewald-estimated versus directly measured low-density lipoprotein cholesterol and treatment implications. J Am Coll Cardiol. 2013; 62(8):732-739.

[6] Oliveira MJ, van Deventer HE, Bachmann LM, Warnick GR, Nakjima K, et al. Evaluation of four different equations for calculating LDL-C with eight different direct HDL-C assays. Clin Chem Acta 2013; 423:135-140.

[7] Scharnagl H, Nauck M, Wieland H, März W. The Friedewald formula underestimates LDL cholesterol at low concentrations. Clin Chem Lab Med. 2001; 39(5):426-431.

[8] Bachorick PS, Ross JW. National Cholesterol Education Program [3] recommendations for measurement of low density lipoprotein cholesterol: executive summary. Clin Chem. 1995; 41(10):1414-1420.

[9] Bairaktari ET, Seferiadis KI, Elisaf MS. Evaluation of methods for the measurement of low-density lipoprotein cholesterol. J Cardiovasc Pharmacol Therapeut. 2005; 10(1):45-54.

[10] Martin SS, Blaha MJ, Elshazly MB, Toth PP, Kwiterovich PO, et al. Comparison of a novel method vs the Friedewald equation for estimating Low-density lipoprotein cholesterol levels from the standard lipid profile. JAMA 2013; 310(19): 2061-2068.

[11] National cholesterol education program (NCEP) Expert panel on detection, evaluation, and treatment of high blood cholesterol in adults (Adult Treatment Panel III). Third report of the national cholesterol education program (NCEP) expert panel on detection, evaluation, and treatment of high blood cholesterol in adults (Adult Treatment Panel III) final report. Circulation. 2002; 106(25):3143-3421.

[12] Grundy SM, Cleeman JI, Merz CN, Brewer HB, Clark LT, et al. National Heart, Lung, And Blood Institute; American College of Cardiology Foundation; American Heart Association. Implications of recent clinical trials for the national cholesterol education program adult treatment panel III guidelines. Circulation. 2004; 110(2):227-239.

[13] Genest J, McPherson R, Frohlich J, Anderson T, Campbell N, et al. 2009 Canadian Cardiovascular Society/Canadian guidelines for the diagnosis and treatment of dyslipidemia and prevention of cardiovascular disease in the adult-2009 recommendations. Can J Cardiol. 2009; 25(10):567-579.
[14] Reiner Z, Catapano AL, De Backer G, Graham I, Taskinen $\mathrm{MR}$, et al. ESC/EAS guidelines for the management of dyslipidaemias: The task force for the management of dyslipidaemias of the European Society of Cardiology (ESC) and the European Atherosclerosis Society (EAS). Eur Heart J. 2011; 32(14):1769-1818.

[15] Smith SC, Benjamin EJ, Bonow RO, Braun LT, Creager MA, et al. World Heart Federation and the Preventive Cardiovascular Nurses Association. AHA/ACCF secondary prevention and risk reduction therapy for patients with coronary and other atherosclerotic vascular disease: 2011 update: A guideline from the American Heart Association and American College of Cardiology Foundation. Circulation. 2011; 124(22):24582473.

[16] Baigent C, Keech A, Kearney PM, Blackwell L, Buck G, et al. Cholesterol Treatment Trialists' (CTT) Collaborators. Efficacy and safety of cholesterol-lowering treatment: prospective meta-analysis of data from 90056 participants in 14 randomised trials of statins. Lancet. 2005; 366(9493):12671278.

[17] Baigent C, Blackwell L, Emberson J, Holland LE, Reith C, et al. Cholesterol Treatment Trialists' (CTT) collaboration. Efficacy and safety of more intensive lowering of LDL cholesterol: a meta-analysis of data from 170000 participants in 26 randomised trials. Lancet. 2010; 376(9753):1670-1681.

[18] Sha MFR, Siddique AH, Saiedullah M, Khan MAH. Evaluation of recently developed regression equation with direct measurement of low-density lipoprotein cholesterol in a Bangladeshi population. J Enam Med Col. 2015; 5(2):75-79.

[19] Martin SS, Giugliano RP, Murphy SA, Wasserman SM, Stein EA, et al. Comparison of low-density lipoprotein cholesterol assessment by Martin/Hopkins estimation, Friedewald estimation, and preparative ultracentrifugation, JAMA Cardiol. 2018; 3(8):749-753.

[20] Palmera MK, Barterb PJ, Lundmanc P, Nicholls SJ, Toth PP et al. Comparing a novel equation for calculating low-density lipoprotein cholesterol with the Friedewald equation: A VOYAGER analysis. Clin Biochem. 2019; 64:24-29. 